\title{
Service Quality and Competitive Strategies in Online Banking
}

\author{
Kuan-Yu Chen ${ }^{\mathrm{a}}$, Sang-Bing Tsai ${ }^{\mathrm{b}, \mathrm{c}, *}$ \\ ${ }^{a}$ Business School, Nankai University, Tianjin 300071, China \\ ${ }^{\mathrm{b}}$ Law School, Nankai University, Tianjin 300071, China \\ ${ }^{\mathrm{c}}$ Zhongshan Institute, University of Electronic Science and Technology of China, Guangdong \\ 528402, China \\ *Corresponding author: Sang-Bing Tsai, Prof., E-mail: sangbing@hotmail.com
}

\begin{abstract}
Online banking is an affordable service that reduces labor costs and risk of human error. Moreover, it overcomes spatiotemporal limitations and enables banks to increase their customers. However, in highly competitive online financial markets, the banking and financial industries are faced with the challenge of becoming industry leaders through improving their service quality and implementing competitive strategies. To examine the online banking service quality of a case company and provide a reference for improving the company, this study incorporated the importance-performance analysis model, which is a frequently adopted model for analyzing the business performance and competitive strategies of companies.
\end{abstract}

Key words: online banking; service quality; competitive strategy; importance-performance analysis model; performance

\section{Introduction}

The twenty-first century is an information era in which customers have constantly evolving needs and fast-paced lifestyles. Using the fastest and most convenient transaction methods is desirable when seeking to access high-quality services and products. Hence, online banking was introduced.

Online banking refers to various types of services that enable bank customers to carry out most regular retail banking services (e.g., balance reporting, transfers, and bill payments) through telecommunication networks without leaving work or home. ${ }^{1}$ Online banking is the use of high-technology products such as digital televisions and mobile phones to carry out bank transactions over the Internet. ${ }^{2}$ Thus, in the present study, we define online banking as a type of service through which customers can perform various banking and financial transactions (e.g., deposits, remittances, transfers, payments, securities orders, insurance services, and interest rate inquiries) by using electronic devices at any time and place without personally attending a bank. Therefore, an online banking service can be regarded as a type of virtual branch established by bank corporations on the Internet for people to perform bank transactions in a more convenient manner. 
The key factors to the service quality of online banking continue to be explored today because of the everchanging needs of customers. Previously, customers were concerned only with the safety and ease of operating online banking interfaces. As online banking evolved, customers began focusing on other factors such as the information content and professionalism and attitudes of customer service personnel in online banking. These additional factors have provided banks with opportunities to derive competitive advantages and enhance customer satisfaction with online banking.

The importance-performance analysis (IPA) model has been frequently used to measure the business performance of corporations and to analyze their competitive strategies. The present study adopted the IPA model to analyze the service performance of a case company in online banking and to provide a reference for that company to improve its business performance.

\section{Literature Review}

\subsection{Definition and Measurement of E-Service Quality}

To motivate customer repurchases and establish customer loyalty, companies should shift their focus from e-commerce transactions to e-services. Companies must understand their customers' experiences and assess their online customer services to improve service quality. This concerns the definitions and measurement of e-service quality.

In contrast to conventional e-commerce services, which emphasize productivity, efficiency, and cost minimization to generate profits, e-services accentuate improving customer satisfaction to acquire lifetime customers, thereby increasing sales and profits. ${ }^{3}$

E-service quality comprises the following seven dimensions: ${ }^{4}$

(1) Efficiency: Inquiry convenience and speed, website ease of use and transaction speed.

(2) Reliability: Website stability and transaction smoothness.

(3) Fulfillment: Accuracy of orders, deliveries, and the service content of web services.

(4) Privacy: Extent to which the website guarantees transaction security and personal data protection.

(5) Responsiveness: Ability, flexibility, and processing quality of the website in solving customer problems.

(6) Compensation: Compensation for customers when they encounter problems with the website.

(7) Contact: Access to customer services and assistance from the website.

From these seven dimensions, the following 10 indices were formulated for the present study to measure online banking service quality and performance: site guidance, functional operation, transaction inquiry, privacy, security and accuracy, bank credibility and valuation, customer compensation for transaction errors, service attitude, service efficiency, and professionalism. 


\section{Research Methods}

The IPA model was developed and applied by Martilla and James. ${ }^{5}$ As shown in Fig. 1, the IPA model depicts the importance and performance of service attributes as a two-dimensional chart, with importance along the vertical axis and performance along the horizontal axis. ${ }^{6-10}$ The four quadrants of the IPA model are defined as follows ${ }^{11-15}$ :

1. Concentrate here: High importance and low performance for a product or service attribute.

2. Keep up the good work: High importance and high performance for a product or service attribute.

3. Low priority: Low importance and low performance for a product or service attribute.

(4) Possible overkill: Low importance and high performance for a product or service attribute.

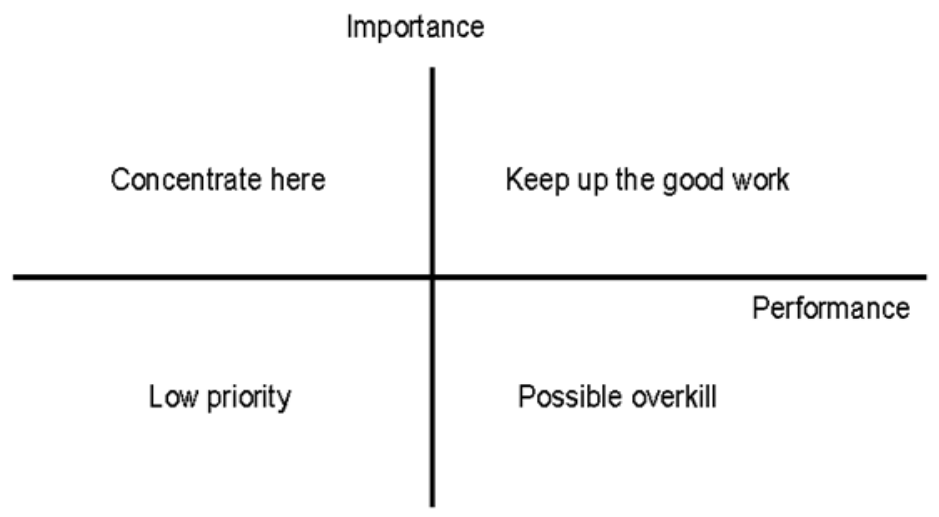

Fig. 1 - IPA model

According to the quadrants in which the indices are located, managers can economize the use of limited resources and prioritize attributes requiring improvement, thereby enhancing business performance and customer satisfaction. ${ }^{16-20}$

\section{Results and Discussion}

This study examined the online banking service quality and competitive strategy of Bank A, the largest commercial bank in Taiwan. A questionnaire containing the aforementioned 10 indices measured through a 7-point Likert scale ( $1=$ anchor, 7 = anchor $)$ was applied to survey 10 professors, 20 bank executives, and 3 government officers. A total of 33 questionnaires were distributed; 32 valid questionnaires were returned (valid return rate, 96.97\%).

The performance of each index was evaluated according to the mean importance (5.87) and performance (5.80) scores, as shown in Table 1. 
Table 1 - Measured online banking service quality and competitive strategies

\begin{tabular}{llcll}
\hline $\begin{array}{l}\text { Index } \\
\text { Number }\end{array}$ & Item & Importance & Performance & Competitive Strategy \\
1. & Site guidance & 5.5 & 5.4 & Low priority \\
2. & Functional operation & 5.7 & 5.6 & Low priority \\
3. & Transaction inquiry & 5.3 & 5.9 & Possible overkill \\
4. & Privacy & 6.1 & 6.2 & Keep up the good work \\
5. & Security and accuracy & 6.2 & 5.9 & Keep up the good work \\
6. & Bank credibility and valuation & 6.0 & 5.9 & Keep up the good work \\
7 & Customer compensation for & 5.9 & 6.3 & Keep up the good work \\
& transaction errors & & & \\
8 & Service attitude & 5.9 & 5.5 & Concentrate here \\
9 & Service efficiency & 6.0 & 5.6 & Concentrate here \\
10 & Professionalism & 6.1 & 5.7 & Concentrate here \\
Mean & & 5.87 & 5.80 & \\
\hline A & & &
\end{tabular}

According to the IPA result, the e-service quality and competitive strategies of Bank A were analyzed as follows:

1. High-importance, high-performance: Indices 4 (privacy), 5 (security and accuracy), 6 (bank credibility and valuation), and 7 (customer compensation for transaction errors) were located in the quadrant "Keep up the good work." These are the competitive advantages of Bank A in online banking and should be maintained to ensure that the bank maintains optimal service quality.

2. High-importance, low-performance: Indices 8 (service attitude), 9 (service efficiency), and 10 (professionalism) were located in the quadrant “Concentrate here.” Bank A must invest additional resources into improving these three indices to reverse its disadvantages and improve its competitive performance.

3. Low-importance, low-performance: Indices 1 (site guidance) and 2 (functional operation) were located in the quadrant "Low priority." These two indices should receive the lowest propriety and be improved only when Bank A has a surplus of resources.

4. Low-importance, high-performance: Index 3 (transaction inquiry) was located in the quadrant "Possible overkill.” The high performance by Bank A on this index did not improve its service quality. The resources invested into this index should be shifted to the other indices. 


\section{Conclusion}

Bank transactions have been extended from manual processing at bank counters to online transactions through information technology. Replacing manual services with online banking transactions reduces labor costs considerably. Additionally, online banking is a service that can be delivered at any time any location. Thus, spatial limitations in banking services are overcome, bank service times are extended, and consumers are provided with more diverse and convenient means for various bank investments and transactions.

In this study, 10 indices were created to assess the quality and performance of online banking services. As shown in the IPA results, the service attitude, service efficiency, and professionalism of Bank A were unsatisfactory; the bank must invest additional resources to improve these indices to reverse its disadvantages and enhance its competitive performance. By contrast, the bank performed satisfactorily on its privacy guarantee, security and accuracy, credibility and valuation, and customer compensation for transaction errors. The bank should maintain these competitive advantages to ensure optimal service quality and performance.

\section{References}

1. A.M.Aladwani, 2001. Online Banking: A Field Study of Drivers, Development Challenges, and Expectations. International Journal of Information Management, 21(3), 213-225.

2. C. Sayar, and S.Wolfe, 2007. Internet Banking Market Performance: Turkey Versus the UK. International Journal of Bank Marketing, 25(3), 122-141.

3. R.T. Rust, and P.K.Kannan, 2003. E-Service: A New Paradigm for Business in the Electronic Environment. Communications of the ACM, 46(6), 37-42.

4. V.A. Zeithaml, A. Parasuraman, and A.Malhotra, 2002. Service Quality Delivery through Web Sites: A Critical Review of Extant Knowledge. Academy of Marketing Science, 30(4), 362-375.

5. J. A. Martilla, and J. C.James, 1977. Importance-Performance Analysis. Journal of Marketing, 41 (1), 77-79.

6. S. B. Tsai , Y. C.Lee, C. H. Wu, and J. J. Guo, 2013. Examining How Manufacturing Corporations Win Orders. South African Journal of Industrial Engineering 24(3): 112-124.

7. Y.C. Lee, C.Y. Chen, S.B. Tsai, and C.T. Wang, 2014. Discussing green environmental performance and competitive strategies. Pensee 76 (7), 190-198. 
8. W.F. Guo , J. Zhou, C.L. Yu, S.B.Tsai, et al. 2015. Evaluating the green corporate social responsibility of manufacturing corporations from a green industry law perspective. International Journal of Production Research 53 (2), 665-674.

9. S. B. Tsai, M.F. Chien, Y. Xue, L.Li, et al. 2015a. Using the Fuzzy DEMATEL to determine Environmental Performance: A Case of Printed Circuit Board Industry in Taiwan. Plos One 10(6): e0129153. doi:10.1371/journal.pone.0129153.

10. S. B. Tsai, R. Saito, Y. C. Lin, Q.Chen, et al. 2015b. Discussing measurement criteria and competitive strategies of green suppliers from a Green law Perspective. Proceedings of the Institution of Mechanical Engineers. Proceedings of the Institution of Mechanical Engineers, Part B: Journal of Engineering Manufacture 229(S1): 135-145.

11. Y.C.Lee, C.H. Wu, and S.B.Tsai, 2014. Grey System Theory and Fuzzy Time Series Forecasting for the Growth of Green Electronic Materials. International Journal of Production Research, 299(8), 1395-1406.

12. J.J.Guo and S.B. Tsai, 2015. Discussing and evaluating green supply chain suppliers: A case study of the printed circuit board industry in China. South African Journal of Industrial Engineering 26 (2), 56-67.

13. S. B. Tsai, Y. Xue, P. Y. Huang, et al. 2015. Establishing a criteria system for green production. Proceedings of the Institution of Mechanical Engineers, Part B: Journal of Engineering Manufacture 229(8): 1395-1406.

14. S.B.Tsai, C.Y. Huang, C.K. Wang, Q.Chen, et al. 2016. Using a Mixed Model to Evaluate Job Satisfaction in High-Tech Industries. Plos One, 11(5): e0154071. doi:10.1371/journal.pone.0154071

15. S.B. Tsai, 2016. Using Grey Models for Forecasting China's Growth Trends in Renewable Energy Consumption. Clean Technologies and Environmental Policy, 18, 563-571.

16. S.B.Tsai, Y.C.Lee, and J.J. Guo, 2014. Using Modified Grey Forecasting Models to Forecast the Growth Trends of Green Materials. Proceedings of the Institution of Mechanical Engineers, Part B: Journal of Engineering Manufacture, 228(6), 931-940.

17. J. Zhou, Q. Wang, S.B. Tsai, et al. 2016. How to Evaluate the Job Satisfaction of Development Personnel. IEEE Transactions On Systems Man Cybernetics-Systems. 10.1109/TSMC.2016.2519860.

18.J.J. Guo, and S.B.Tsai, 2015. Discussing and Evaluating Green Supply Chain 
Suppliers: A Case Study of the Printed Circuit Board Industry in China. South African Journal of Industrial Engineering, 26(2), 56-67.

19. J.M. Su, S.C. Lee, S.B.Tsai, et al. 2016. A Comprehensive Survey of the Relationship between Self-efficacy and Performance for the Governmental Auditors. SpringerPlus, 5:508. DOI: 10.1186/s40064-016-2104-x.

20. Q. Qu, K.Y.Chen, Y.M.Wei, et al. 2015. Using Hybrid Model to Evaluate Performance of Innovation and Technology Professionals in Marine Logistics Industry Mathematical Problems in Engineering, Article ID 361275, 8 pages, http://dx.doi.org/10.1155/2015/361275. 